Sherris, J. C., Preston, N. W. \& Shoesmith, J. G. (1957). J. gen. Microbiol. 16, 86-96

\title{
The Influence of Oxygen and Arginine on the Motility of a Strain of Pseudomonas sp.
}

\author{
By J. C. SHERRIS, N. W. PRESTON ANd J. G. SHOESMITH \\ Department of Bacteriology, University of Manchester
}

SUMMARY : The motility of a strain of Pseudomonas sp. was activated by molecular oxygen or by arginine. In the presence of sufficient oxygen to support motility, arginine was not required for this purpose. In the absence of sufficient oxygen, arginine supported motility and was broken down to ornithine; there is not yet enough evidence to indicate whether this breakdown supplied the energy for such arginine-activated motility. In the presence or absence of arginine, the organism exhibited chemotaxis towards an optimum oxygen concentration which was less than that at the air/suspension interface.

As part of another investigation some heat-killed tubercle bacilli were disintegrated with small glass beads and the resulting material stored in the refrigerator at $4^{\circ}$. Some weeks later it was observed that the turbidity of the suspension had markedly increased, and a drop was examined microscopically on a glass slide under a coverslip. This revealed contaminating bacilli which at first were highly motile throughout the preparation, but after a few minutes lost their motility abruptly except around bubbles of air trapped under the coverglass. The organism was isolated and experiments were undertaken to determine the factors responsible for its selective motility; some of the results of these investigations have already been briefly reported (Preston \& Sherris, 1955). The present paper is concerned with a more detailed description of those experiments and the results of further work.

\section{METHODS}

Organism used. The organism studied had the following characters: short Gram-negative rod, usually with a single polar flagellum, but sometimes lophotrichate or amphitrichate; viscid growth on nutrient agar at $23^{\circ}, 48 \mathrm{hr}$. colonies 1-2 mm. diameter; turbidity in broth most marked near the surface, viscid deposit in older cultures; green fluorescent water-soluble pigment produced; gelatin liquefied; urease produced; nitrate not reduced to nitrite; indole and hydrogen sulphide not produced; alkaline reaction in litmus milk; growth in Koser's citrate; acid produced from glucose and sucrose, but no fermentation of lactose, maltose, salicin, mannitol, dulcitol; strict aerobe; good growth at $23^{\circ}-30^{\circ}$, no growth at $37^{\circ}$.

The possession of these characters presents no difficulty in assigning this strain to the genus Pseudomonas. Descriptions of species within the genus, however, are far from complete; excluding the plant pathogens (since we have no information on its pathogenicity) this organism most closely resembles $\boldsymbol{P}$. viscosa as described in Bergey's Manual (1948), and the above properties 
differ from this description only in the inability of our strain to grow anaerobically. The organism used here will subsequently be referred to as 'the pseudomonad'.

Preparation of bacterial suspension. After overnight growth of the pseudomonad on nutrient agar at $\mathbf{2 3}^{\circ}$, the bacteria were carefully removed from the surface of the medium and suspended in distilled water; the viscosity of these young cultures was not sufficient to prevent the ready preparation of homogeneous suspensions. The concentration of organisms in such suspensions was standardized so that the final preparation when mixed with other reagents would be equivalent in turbidity to Brown's opacity tube no. $5\left(c .4 \times 10^{9}\right.$ organisms $/ \mathrm{ml}$.). Unless otherwise stated, all preparations were adjusted to pH 7.2 with Kolthoff's buffer (final concentrations: 14.5 mu-potassium dihydrogen phosphate, 5·25 mu-borax).

Preparations for microscopical examination. Flat capillary tubes at least $50 \mathrm{~mm}$. long were prepared from glass tubing by a modification of the method of Wright \& Colebrook (1921). The material to be examined for motility was drawn into these tubes, leaving at one end a space containing air or some other gas. The tubes were then sealed, mounted on microscope slides with plasticine and examined under the $4 \mathrm{~mm}$. objective. Resolution was excellent and distances from the meniscus were readily measured with the vernier on the microscope stage.

Gases other than air were introduced into the preparations by the following method. One end of the capillary tube was attached by rubber tubing to a cylinder of the appropriate gas and the other end held beneath the surface of a bacterial suspension. After allowing sufficient time for the air in the tube to be entirely replaced by the gas, the cylinder was closed and the rubber tubing squeezed and then released to withdraw a column of suspension into the capillary tube. The tube was then sealed at both ends, leaving the bacterial suspension in contact with the gas at the end which had been attached to the cylinder.

Estimation of arginine, ornithine and ammonia. Arginine concentrations were measured colorimetrically by the method of Sakaguchi (1950). Ornithine concentrations were determined by the method of Chinard (1952) in which ornithine reacts with ninhydrin in an aqueous acetic + phosphoric acid solution at $100^{\circ}$ to give a red colour. Ammonia estimations were made by the phenol hypochlorite method of Lubochinsky \& Zalta (1954). All colorimetric readings were made with a Hilger 'Biochem' absorptiometer.

\section{RESULTS}

\section{Activation of motility by oxygen}

The influence of air on motility. When aqueous suspensions of the pseudomonad were introduced into flat capillary tubes the organisms were at first actively motile throughout the length of the liquid; but after several minutes motility ceased abruptly except in a zone extending for about 3-4 mm. from the air space. By taking great care not to aerate the suspension during 
transfer to the capillary tube, the duration of general motility could be decreased to 2-3 min., whereas previous deliberate and prolonged aeration enabled it to continue up to $80 \mathrm{~min}$. In the zone near the air bubble, however, the organisms remained motile for many days at room temperature, the actual duration depending on the volume of the air space. These findings indicated that motility was dependent upon some expendable component of the air. This was confirmed by the observation that when a capillary tube was reopened after all motility had ceased, the organisms immediately became actively motile again in the zone near the air space. One such tube was opened and resealed five times over a period of 2 months, and motility was re-established on each occasion.

The effect of other gases on motility. When oxygen was introduced into a capillary tube in place of air, general motility throughout the length of the suspension again ceased after a few minutes, but the residual motile zone now extended for about $8 \mathrm{~mm}$. from the meniscus. The introduction of nitrogen, hydrogen or carbon dioxide into the capillaries, however, failed to support motility at any point in the suspension after the initial brief period of general motility had ceased. These findings indicated that the initial general motility was due to dissolved oxygen, and that the continuing motility in the zone near the air/suspension interface was due to the oxygen content of the air. These phenomena will be referred to respectively as 'general aerobic motility' and 'superficial aerobic motility'.

Chemotactic effect of oxygen. In the initial observations on suspensions which were examined on glass slides under coverslips, it was noticed that the bacteria tended not only to exhibit maximum motility around air bubbles but also to accumulate there. It was not clear whether this apparent movement of organisms towards the air was due to some physical effect such as surface tension or even a lateral expansion of the bubble, or whether it constituted a true chemotaxis. The following results, obtained with suspensions in flat capillary tubes, indicate that oxygen does exert a chemotactic effect on the organisms. Approximately $20 \mathrm{~min}$. after setting up a preparation, the zone of superficial aerobic motility was seen to be differentiated into three parts. Nearest the air space was a section in which the organisms were moderately motile, and adjacent to this was a zone of increased motility and apparent concentration of the organisms. Beyond this was a small zone of definite rarefaction separating the motile from the non-motile portions of the suspension; this zone of rarefaction was readily visible macroscopically as well as microscopically.

After several days the non-motile organisms settled to the bottom of the tube and the highly motile and concentrated zone became increasingly apparent as a sharply defined band. In one experiment such a preparation was observed daily for 3 weeks. After 6 days the band was $\mathbf{0 . 1} \mathrm{mm}$. across and was found to move gradually towards the meniscus (see Table $1 a$ ). Just before it reached the meniscus the tube was reopened and within a few minutes the band was moving back along the tube away from the opened air space (see Table $1 b$ ). This rapid change in position of the band of highly motile organisms 
was not due to resuspension of deposited bacteria in a region of optimal oxygen concentration, for had this been the case, large numbers of resuspended organisms would have been left behind as the band retreated from the meniscus. This did not occur, for the zone between the meniscus and the moving band was almost free from suspended bacteria. The highly motile organisms which formed the band were thus moving en masse as oxygen diffused into the suspension, and were exhibiting chemotaxis towards a concentration of oxygen less than that in air and apparently optimal for their activity. This chemotactic phenomenon in the zone of superficial aerobic motility was also noted when arginine was present in the bacterial suspension.

\section{Table 1. Chemotactic effect of oxygen}

(a) Movement of narrow band of highly motile pseudomonads towards air/suspension interface in sealed capillary tube

Time from sealing tube (days) $\quad \ldots \quad 6 \quad 6 \quad 11$

Distance of band from meniscus (mm)

$\begin{array}{rrrrr}\text { Distance of band from meniscus (mm.) } & 2.9 & 1.7 & 1.0 & 0.2\end{array}$

(b) Movement of band away from meniscus after reopening tube

$\begin{array}{lllllll}\text { Time from reopening tube (min.) } & \ldots & 0 & 4 & 14 & 42 & 107\end{array}$

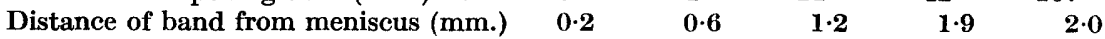

\section{Activation of motility by arginine}

Maintenance of motility by nutrient broth. The observations so far recorded were made on aqueous suspensions of the pseudomonad; but different results were obtained when a double-strength suspension was mixed with an equal volume of nutrient broth before examination in a capillary tube. Observations were now confined to those parts of the suspension which were more than $20 \mathrm{~mm}$. from the air space, i.e. regions where motility in aqueous suspensions ceased after a few minutes. The organisms in nutrient broth became nonmotile, following the period of general aerobic motility, at approximately the same time as those in aqueous suspensions; but, after a pause of a few seconds, the broth suspension again exhibited motility which continued for at least $40 \mathrm{~min}$. (see Fig. 1). These findings led to an examination of the constituents of broth in a search for some factor capable of reactivating this 'deep' motility.

Investigation of factors in broth responsible for reactivating motility. It seemed possible that the restored deep motility seen in broth suspensions might be due to the gradual release of oxygen or to a higher oxidation-reduction potential than that in aqueous suspensions. However, the results obtained with untreated broth could be reproduced with boiled broth, Brewer's medium, or broth containing $0.1 \%(\mathrm{v} / \mathrm{v})$ mercaptoacetic (thioglycollic) acid. These findings, together with the brief pause in motility which occurred in broth, indicated that the restored motility was due to mechanism different from that which was activated by oxygen. Further search showed that digest broth or a $1 \%(\mathrm{w} / \mathrm{v})$ solution of peptone was active but meat extract (without added peptone) and the supernatant fluid from an overnight broth culture of the 
organism were without effect. This suggested that the responsible factor was a product of protein breakdown used by the organism during growth, and thus led to an investigation of amino acids.

Twenty-two amino acids were tested separately in final concentrations of 5 , 0.5 , and 0.05 mM. They were: glycine, DL-alanine, DL-valine, DL-leucine, DL-isoleucine, DL-serine, DL-threonine, L-cysteine, DL-methionine, L-aspartic acid, L-asparagine, I-glutamic acid, DL-lysine, L-arginine, L-citrulline, L-ornithine, glycocyamine, creatine, DL-histidine, L-proline, L-hydroxyproline, DL-

Aqueous suspension

A. Immediately after introduction into capillary tube
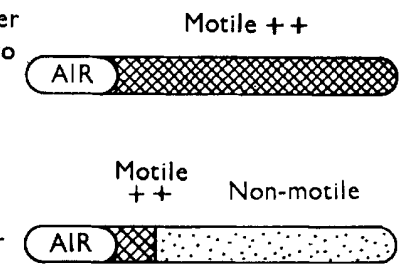

B. Few minutes later

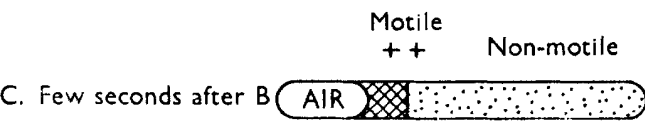

Aqueous suspension mixed with broth or arginine

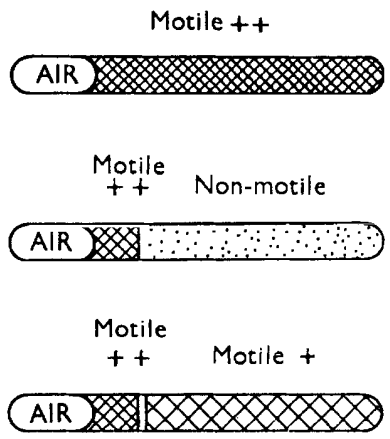

Fig. 1. The effect of air, and broth or arginine, on the motility of suspensions of the pseudomonad when studied in capillary tubes.

phenylalanine. $\mathrm{I}_{1}$-Tyrosine and DL-tryptophan were tested in concentrations of 0.5 and $0.05 \mathrm{~mm}$. Of these amino acids only L-arginine was capable of restoring deep motility, and at $0.5 \mathrm{~mm}$ maintained it for $45 \mathrm{~min}$. This restored motility activated by arginine and occurring after the brief pause which followed the period of general aerobic motility will be referred to as 'arginine-activated motility'.

Quantitative effect of arginine. The duration of arginine-activated motility was directly proportional to the concentration of arginine in the suspension

Table 2. Relationship between duration of arginine-activated motility and concentration of arginine

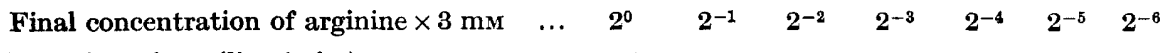

$\begin{array}{lllllllll}\text { Duration of motility (min.) } & 182 & 86 & 43 & 22 & 12 & 7 & 2\end{array}$

over the range $3 \mathrm{~mm}$ to $50 \mu \mathrm{M}$ (see Table 2). A linear relationship did not apply, however, when much higher concentrations of arginine were used, for a fourfold increase in arginine concentration (from 3 to $12 \mathrm{~mm}$ ) resulted in an increase in the duration of motility from $3 \mathrm{hr}$. to more than $21 \mathrm{hr}$. This proportionately greater increase in the duration of motility was associated with more sluggish movement of the organisms and with the development of a markedly alkaline reaction $(\mathrm{pH}>\mathbf{8 \cdot 2})$ in the capillaries. An 
experiment was therefore made to test the effect of alterations in $\mathrm{pH}$ value on the duration of arginine-activated motility. The results (see Table 3) showed that a reaction more alkaline than $\mathrm{pH} 7 \cdot 6$ caused an increase in the duration of motility, an increase which was again accompanied by more sluggish movement of the bacteria.

Table 3. The influence of $\mathrm{pH}$ value on the duration of arginine-activated motility

Arginine concentration $0.4 \mathrm{~mm}$.

$\begin{array}{lcccccc}\text { pH of buffered suspension ... } & 6 \cdot 6 & 7 \cdot 0 & 7 \cdot 4 & 7 \cdot 8 & 8 \cdot 2 & 8 \cdot 6 \\ \text { Duration of motility (min.) } & 21 & 20 & 22 & 23 & 42 & >120\end{array}$

The relationship of arginine breakdown to motility. A standard suspension of the pseudomonad was made in buffered saline consisting of $\mathrm{m} / \mathbf{3 0}$ phosphate buffer $(\mathrm{pH} 7 \cdot 2)$ and $0.5 \%(\mathrm{w} / \mathrm{v}) \mathrm{NaCl}$. After allowing equal volumes of this suspension and of a solution of arginine $(1 \mathrm{~mm})$ in buffer to equilibrate in a water bath at $23^{\circ}$, they were mixed and quickly distributed in $4 \mathrm{ml}$. amounts to narrow tubes $\left(9 \times 90 \mathrm{~mm}\right.$.). The tubes were incubated at $23^{\circ}$, removed at suitable intervals, and the contents allowed to drain into $1 \mathrm{ml}$. of $5 \%(\mathrm{w} / \mathrm{v})$ trichloroacetic acid. The organisms were removed by centrifugation and the arginine concentrations in the supernatant fluids determined. The motility of the suspension was examined by filling capillaries from the tubes at intervals and examining them microscopically. The conditions under which the reaction was allowed to proceed were chosen to resemble those found in capillary tubes on the microscope stage, i.e. a small surface area in contact with air and a temperature of $23^{\circ}$. That this end was achieved is shown by the fact that motility ceased at the same instant in all capillaries, though these were filled from the reaction mixtures at various time intervals. This did not occur when the mixtures were incubated in wide tubes, or at a different temperature from that found on the microscope stage.

The results show (Fig. 2a) that little or no breakdown of arginine occurred during the period of general aerobic motility. After the brief cessation of motility in the deeper parts of the capillary tubes arginine-activated motility began and arginine was decomposed at a steady rate. Motility ceased when all the arginine had been broken down.

The relationship between arginine breakdown and arginine-activated motility was found to be independent of the duration of the preceding period or general aerobic motility. When suspensions containing arginine were briskly aerated before distribution to narrow tubes, there was no breakdown of arginine during aeration or the subsequent period of prolonged general aerobic motility. The period of arginine-activated motility still corresponded, however, to the period of arginine breakdown (Fig. $2 b$ ).

\section{The fate of arginine}

Chromatographic analysis. A bacterial suspension prepared in $\mathrm{M} / 80$ phosphate buffer ( $\mathrm{pH} \mathrm{7 \cdot 2)}$ was incubated in the presence of $20 \mathrm{~mm}$ arginine at $18^{\circ}$. Samples were removed at hourly intervals for $6 \mathrm{hr}$., centrifuged, and the 
supernatant fluids examined by chromatography. The chromatograms were run on Whatman no. 1 paper with an ascending boundary, using phenol saturated with water as the mobile phase. On spraying the chromatogram with a ninhydrin solution spots corresponding to arginine were found in all samples, while others, corresponding to ornithine, appeared in samples derived from reaction mixtures which had been incubated for more than $1 \mathrm{hr}$. No spots developed corresponding to citrulline or any amino acid other than arginine and ornithine. Similar chromatographic methods were applied to mixtures of bacterial suspension and citrulline. There was no evidence of citrulline breakdown, and no ornithine was produced.

(a) Unaerated suspension

(b) Aerated suspension
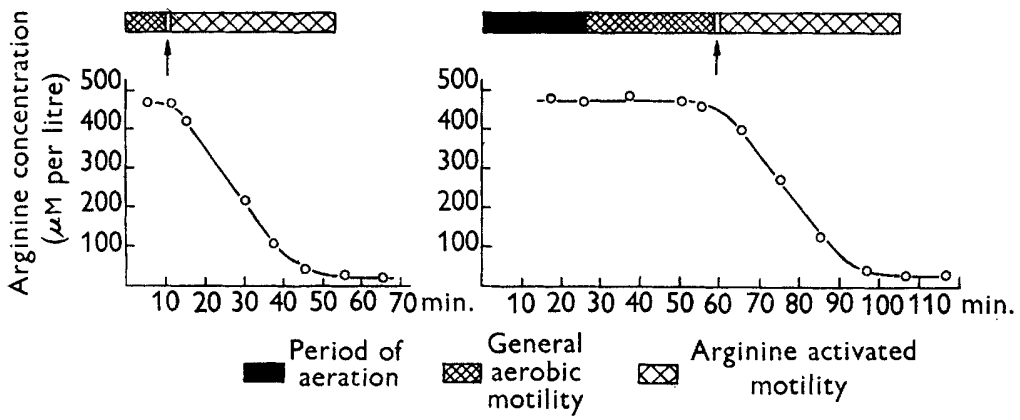

At the point indicated by the arrow motility ceased completely for a few seconds

Fig. 2. The relationship of arginine breakdown to motility.

Quantitative colorimetric determinations. Arginine (final concentration $525 \mu \mathrm{M}$ ) was added to a twice-washed suspension of the pseudomonad in buffered saline. The reaction mixtures were maintained at $23^{\circ} ; 4$ ml. samples were removed at intervals and allowed to drain into $1 \mathrm{ml} .5 \%(\mathrm{w} / \mathrm{v})$ trichloroacetic acid and the mixtures heated at $100^{\circ}$ for $15 \mathrm{~min}$. to ensure that the products of the reaction were extracted from the organisms. These were then removed by centrifugation and colorimetric estimations of arginine, ornithine and ammonia were made on the supernatant fluids. A suspension without added arginine was similarly treated to obtain blank values.

The results in Table 4 show that, within experimental error, all the arginine broken down could be accounted for as ornithine and ammonia. The possibility was considered that the initial breakdown of arginine was to ornithine and urea, and that the urease elaborated by the organism decomposed urea as it was formed. Urease activity in culture was, however, detected only after incubation on a urea-containing medium for 3 days, whereas there was no detectable breakdown of added urea (concentration $500 \mu \mathrm{M}$ ) within $1 \mathrm{hr}$. by suspensions of the organism. Moreover, treatment of the supernatant fluids with urease failed to increase the amount of ammonia present. These findings 
indicate that the hydrolysis of the arginine was brought about by an enzymic process similar to the arginine dihydrolase system of Hills (1940), rather than by the mammalian type of arginase.

Table 4. Relationship of ornithine and ammonia production to

Time from
addition of
arginine
(min.)
0
20
40
60
80
arginine breakdown

$\begin{array}{ccc}\begin{array}{c}\text { Arginine } \\ \text { decomposed } \\ (\mu \text { mole } / 1 .)\end{array} & \begin{array}{c}\text { Ammonia formed } \\ (\mu \text { mole } / 1 .)\end{array} & \begin{array}{c}\text { Ornithine } \\ \text { formed } \\ (\mu \text { mole } / 1 .)\end{array} \\ \mathbf{0} & 2 \times 0 & 0 \\ \mathbf{2 5} & 2 \times 45 & \mathbf{2 5} \\ \mathbf{2 4 5} & 2 \times 250 & \mathbf{2 3 0} \\ \mathbf{4 9 5} & 2 \times 480 & \mathbf{4 9 5} \\ \mathbf{5 2 5} & \mathbf{2} \times \mathbf{5 2 0} & \mathbf{5 2 0}\end{array}$

Blank values. No arginine or ornithine detected. Ammonia $25 \mu \mathrm{mole} / \mathrm{l}$; the figures in the table were obtained by subtraction of the blank reading.

\section{The effect of other reagents on motility}

Other reagents were added to equal volumes of bacterial suspension to test for their ability to prolong general aerobic motility or to reproduce the restored deep motility given by arginine. All materials added gave negative results. They included: adenosine triphosphate $(2.5 \mathrm{mM}$ to $0.25 \mu \mathrm{M})$; urea (25 mM to $0.25 \mathrm{~mm})$; ornithine $(1 \mathrm{mM})+$ ammonium carbonate $(1 \mathrm{~mm})$ to simulate the end products of arginine breakdown by arginine dihydrolase (Hills, 1940); potassium nitrate $(1 \%$ to $0.001 \%, w / v)$; methylene blue $(0.01 \%$ to $0.0001 \%$, $\mathrm{w} / \mathrm{v})$; glucose $(1 \%$ to $0.01 \%, \mathrm{w} / \mathrm{v})$, and modified Proskauer and Beck's medium (quoted by Jensen, 1954) which is a defined medium containing but one amino acid, asparagine, and which supported excellent growth of the pseudomonad. A mixture of adenosine triphosphate $(0.75 \mathrm{~mm}$ to $7.5 \mu \mathrm{M})$ + arginine $(0.4 \mathrm{~mm})$ had no more effect on the duration of arginine-activated motility than that produced by arginine alone.

\section{DISCUSSION}

The findings recorded here show that, in aqueous suspensions of the pseudomonad studied, motility may be activated under aerobic conditions by oxygen, or under relatively anaerobic conditions by arginine. These two processes are qualitatively different, for very little, if any, arginine is broken down during the period of aerobic motility, and motility activated by arginine does not begin until a second or two after the oxygen content of the suspension has fallen below the minimum level needed for aerobic motility. The requirements for aerobic motility reflect those for growth and metabolism of the organism, but arginine is not needed as a nutrient nor does its addition to solid or fluid media allow growth to occur under anaerobic conditions.

As definite information is not at present available about the biochemical processes which supply energy for flagellar activity, it is worth considering how arginine might contribute to this process. One possibility is that the 
energy may be liberated directly by the breakdown of arginine to ornithine; another, more in keeping with present knowledge of other systems which involve biological movement, is that energy-rich phosphates are produced during the arginine breakdown and that they furnish the immediate source of energy. A clue as to how this might be brought about is given by the work of Slade, Doughty \& Slamp (1954) who showed that cell-free extracts of a strain of Pseudomonas sp. isolated from soil converted citrulline to ornithine, carbon dioxide and ammonia in the presence of bivalent ions, inorganic phosphate and adenosine diphosphate (ADP) or adenylic acid. Breakdown of citrulline under these conditions was associated with the formation of adenosine triphosphate (ATP) due to the esterification of the phosphate supplied.

The pseudomonad we have studied resembles that of Slade and his colleagues in that it breaks down arginine, but not ornithine, and it may be that citrulline is produced as an intermediate product as in the case of the cell-free extracts of Streptococcus faecalis studied by Slade (1953). The fact that we have been unable to detect citrulline chromatographically, that it had no effect on motility and that it was not broken down by suspensions of whole organisms, cannot be held to exclude the possibility that ATP, produced by the citrullineureidase reaction of Slade and his colleagues, furnishes the immediate source of energy for motility of our strain. Slade \& Slamp (1952) showed that, in the case of $S$. faecalis, whole organisms were unable to break down citrulline whereas cell-free extracts were active (Slade, 1953). It is possible that the lack of activity of citrulline in our experiments was due to its failure to pass into the pseudomonad.

The possibility may also be considered that arginine is required for some other system and that its breakdown, while limiting the duration of its activity, plays no part in supplying energy for motility. X-ray diffraction studies and chemical analysis of isolated bacterial flagella (Astbury \& Weibull, 1949; Weibull, 1950, 1951) showed that they consist of a protein 'flagellin' (Astbury, Beighton \& Weibull, 1955) which belongs to the keratin-myosinepidermin-fibrinogen group of fibrous-elastic proteins, and these workers conclude that bacterial flagella are effectively monomolecular muscles. Arginine phosphate in invertebrate muscle plays the same role as creatine phosphate in vertebrate muscle. In contraction of invertebrate muscle the reaction arginine phosphate $+\mathrm{ADP} \rightarrow$ arginine $+\mathrm{ATP}$ proceeds from left to right as ATP is broken down by adenosine triphosphatase to liberate energy. When contraction ceases arginine is re-phosphorylated by energy-rich phosphates derived from anaerobic glycolytic processes. If a similar system obtains for storing and providing energy for flagellar activity it is possible that, under conditions in which an arginase is active, the addition of arginine would temporarily allow re-synthesis of sufficient arginine phosphate for motility to proceed.

Both the mechanisms of action of arginine considered above involve the assumption that ATP is the immediate source of energy for flagellar activity; analogy with other biological systems which involve movement (e.g. muscle contraction; mitosis; motility of trypanosomes and spermatozoa; see Weber, 
1955) suggests that this is probably the case. Some evidence on this has been given by De Robertis \& Franchi (1951) who reported contraction of the flagella of Bacillus brevis in the presence of ATP, and by De Robertis \& Peluffo (1951) who found that ATP enhanced the motility of Proteus vulgaris. The lack of activity of ATP in our experiments may, as suggested for citrulline, be due to its failure to pass the permeability barrier of the pseudomonad.

The chemotactic effect of oxygen appears to merit further study, for similar observations were made by Engelmann $(1882,1894)$ with a variety of bacteria. In his later experiments algae were incorporated in the bacterial preparations, and by varying the amount of light impinging on them he was able to vary the local production of oxygen during photosynthesis, and thus obtained a most convincing demonstration of chemotaxis. Some of his bacteria aggregated in the immediate vicinity of the algae, but others were concentrated in a band some distance from the source of oxygen, producing a very similar phenomenon to that observed in our experiments.

Our thanks are due to Dr C. Weibull for drawing our attention to the work of Engelmann.

\section{REFERENCES}

Astbury, W. T., Beighton, E. \& Weibull, C. (1955). The structure of bacterial flagella. In Fibrous Proteins and their Biological Significance. Symp. Soc. exp. Biol. 9, 282.

Astbury, W. T. \& Weibulx, C. (1949). X-ray diffraction study of the structure of bacterial flagella. Nature, Lond. 163, 280.

Bergey's Manual of Determinative Bacteriology (1948). 6th ed. Edited by Breed, R. S., Murray, E. G. D. \& Hitchens, A. P. London: Baillière, Tindall and Cox.

Chinard, F. P. (1952). The photometric estimation of proline and ornithine. J. biol. Chem. 199, 91.

De Robertis, E. \& Franchi, C. M. (1951). Macromolecular structure of the contractile protein of bacterial flagella. IX Meeting of the Electron Microscopists, Society of America, November 1951.

De Robertis, E. \& Peluffo, C. A. (1951). Chemical stimulation and inhibition of bacterial motility studied by a new method. Proc. Soc. exp. Biol., N.Y. 78, 584.

Englemann, T. W. (1882). Zur Biologie der Schizomyceten. Bot. Ztg, 40, 322.

Engelmann, T. W. (1894). Die Erscheinungsweise der Sauerstoffausscheidung chromophyllhaltiger Zellen im Licht bei Anwendung der Bacterienmethode. Arch. Physiol. 57, 375.

HIrLs, G. M. (1940). Ammonia production by pathogenic bacteria. Biochem. J. 34, 1057.

Jensen, K. A. (1954). Towards a standardization of laboratory methods. Bull. Un. int. Tuberc. 24, 78.

Lubochinsky, B. \& Zalta, J. P. (1954). Microdosage colorimétrique de l'azote ammoniacal. Bull. Soc. Chim. biol., Paris, 36, 1363.

Preston, N. W. \& Sherris, J. C. (1955). Factors influencing the motility of a strain of Pseudomonas viscosa. Nature, Lond. 176, 1220.

Saraguchi, S. (1950). A new method for the colorimetric determination of arginine. J. Biochem., Tokyo, 37, 231.

Slade, H. D. (1953). Hydrolysis of arginine by soluble enzymes of Streptococcus faecalis. Arch. Biochem. Biophys. 42, 204. 
Slade, H. D., Doughty, C. C. \& Slamp, W. C. (1954). The synthesis of high-energy phosphate in the citrulline ureidase reaction by soluble enzymes of Pseudomonas. Arch. Biochem. Biophys. 48, 338.

Slade, H. D. \& Slamp, W. C. (1952). The formation of arginine dihydrolase by streptococci and some properties of the enzyme system. J. Bact. 64, 455 .

Weber, H. H. (1955). The link between metabolism and motility of cells and muscles. In Fibrous Proteins and their Biological Significance. Symp. Soc. exp. Biol. 9, 271.

Weibull, C. (1950). Investigations on bacterial flagella. Acta Chem. Scand. 4, 268.

Werburl, C. (1951). Some analytical evidence for the purity of Proteus flagella protein. Acta Chem. Scand. 5, 529.

Wright, A. E. \& Colebrook, L. (1921). Technique of the Teat and Capillary Glass Tube, p. 22. London: Constable.

(Received 4 July 1956) 